\title{
Leprosy in Society \\ III. The Relationship of the Social to the Medical Pathology of Leprosy
}

\author{
OLAF K. SKINSNES, M.D., PH.D.*
}

Two prior publications in this trilogy (Skinsnes, I.ep. Rev. 35, Nos. I \& 3), have pointed to and examined comparatively the pattern of concept and reaction to leprosy in several socicties, East and $W$ est, from carliest recorded times to the present. It is not necessary to assume that the folklore related to leprosy grew out of medical thinking or medical thinking out of folklore. Both, in parallel, and mutually interactive, are a reflection of society's total reaction to the disease; medical thought tending to distill observation and concepts into understanding principles and delineation, and the community at large embroidering and elaborating its fears and fancies into ever expanding ramifications of misunderstanding.

In both Eastern and Western societies, medical practice was long associated with the priestly heirarchy and over the centuries these societies provided religious explanations for observationsconcerning which medicine, in the absence of developed bacteriologic, pathologic and related medical understanding, had no factual answer. For leprosy this association was especially close due to factors that will be examined more closely. Not until recently has medical interest, therapeutic ability, and understanding in leprosy been such as to be able to effectively challenge misconceptions that are hoary with age.

The Orient, as distinct from the Fertile Crescent, in its religious and moral contexts tended to basically regard the sufferer with leprosy as being punished for moral delinquency by affliction with that disease complex which was visually, and therefore obviously, the most horrible known. The Hebrews, representative of Fertile Crescent and derivative Western cultures, likewise tied in religious concepts but emphasized the defilement of uncleanness, using the term 'tsara'ath' to express such defilement. Avoidance of defilement was important to concepts of personal and national relationship with God (Cochrane 1956) and, for the Hebrew therefore also important in their struggle for national entity. Whether or not leprosy was originally a component of the concept of 'tsara'ath' has been questioned by many, notably Tas (I953), and Gramberg (1959). It is clear that the clinical features recognized today as characteristic of leprosy are not described or even mentioned in the Bible. However, the Hebrews were concerned more with 'tsara'ath' as a religious and theological entity than as a medical problem. Unexplained, nevertheless, is their failure to mention the clinical features which would have been helpful in diagnosing the offending condition if leprosy were the object of their

* Department of Pathology, University of Chicago, Ill. 
ire. It would, therefore, seem that to the Hebrews the skin blemish or spot, as symbolic of defilement, of whatever origin, may have been of more concern than the other manifestations more exclusively characteristic of leprosy. Their initial religious reaction may therefore have been predominantly an expression against defilement as symbolized by a skin blemish of any etiology including leprosy, provided the blemish had certain defined characteristics. Quite possibly, at the time that the Hebrews were developing their concepts of 'tsara'ath', leprosy was in the Fertile Crescent and was building up a reaction not unlike that found in the Orient and later in Western society. It seems clear that by the time of the Septuagint translation such a reaction was well defined, as was perhaps also leprosy though still undoubtedly at least partially confused with other conditions. It would appear that the translators of the Septuagint, as translators are wont, sought for some Greek equivalent that would most closely approach and so best define the Hebrew abhorrence of defilement and of 'tsara'ath' as expressive of such defilement. Leprosy, because of society's reaction to it, apparently was the best equivalent and was so used. Since leprosy was perhaps already at least to some degree involved in 'tsara'ath' the translation was apparently acceptable to the contemporaries of the translators. In view of society's deplorable, but continuing reaction to this disease, the translation of the Septuagint even today is probably the closest possible to carrying the concept implied by 'tsara'ath'.

Added to the concepts of religious defilement and of punishment for moral misdemeanor were other accretions and elaborations. Perhaps the most powerful and most universal taboos of society are those related to sex, and in the reaction toward leprosy as the ultimate in moral delinquency, implications of sexual impropriety were added to the supposed misdemeanors of those afflicted with the loathed and feared condition. Thus, Aretaeus (Adams I 856) speaks of 'impulse ad coitum' and Chinese folklore carries the same implication. The treatment of persons with leprosy is similar to that accorded to adulterers in the Old Testament (Bible).

Further implications of the social opprobrium in both East and West have been sufficiently noted in the prior communications of this series to establish the general pattern of social reaction to leprosy. They need not be further elaborated.

\section{'HANSEN'S DISEASE' versus 'LEPROSY'}

Following on the better understanding of leprosy made possible by the development of bacteriologic and pathologic knowledge, a new social reaction has arisen in the form of a revulsion against centuries-perpetuated, unjust and persecutory misconceptions. This is promoted primarily by patients with leprosy and workers in this field of medical and social activity. In a limited portion of the semantic world this revulsion has focused on efforts to change the name of the disease and it is said (Lendrum I945) that, 'A formidable movement is under way to escape from the 
completely unjustified revulsion which the name leprosy excites.' It is further contended that this ' . . purpose can easily be attained by making official the already widely used term 'Hansen's diseasc' in place of a name which has disastrous and altogether crroneous Biblical associations.'

From what has been noted in these historical and social resumés, it would seem that the basic premise offered in these statements is fallacious. In view of the pattern of society's reaction, its history, and its roots, it is questionable if this laudable purpose can indeed be 'easily attained'. 'The term 'leprosy', and its recognizable variants, is limited to those few languages which are primarily prevalent in areas of low, or virtually no leprosy incidence. For most of the Orient and Africa, where leprosy is a distinct public health problem, this specific change is meaningless and even unintelligible to that segment of the population where folklore is most deeply rooted.

The proposed change in name, carried out logically and with a view toward scmantic needs, would require the following supplementary, anomalous terms:
Hansenology - $\quad-\quad$ the study of Hansen.
Hansenophobia - _ $\quad$ - the fear of Hansen.
Hansenitis - _ _ $\quad$ - an infection of Hansen.
Hansenarium - _ $\quad$ - an institution for the care of Hansen (long since departed this world) or peopled with Hansens - hardly practical or significant in China, India, Japan, etc.
Hansenoma - _ $\quad$ a tumerous growth of Hansen.
Hansenomatous reaction - a reaction like Hansen.
Hansenomatous Hansenitis - as contrasted with the other polar type, tuberculoid Hansenitis; that is, an in- fection of Hansen like Hansen.
Erythema nodosum Hansenosum, etc., etc., etc.

This type of nonsenology is probably a major reason why physicians working with leprosy have been, to the chagrin of the proponents, less than co-operative in complying with the suggested change. Indeed, since Hansen did not have leprosy, it is even more anomalous to speak of 'Hansen's Disease,' admitting that similar prior mistakes have been made with respect to other diseases. In this case it might be more logical, if indeed there is logic in this procedure, to speak of 'Damien's Disease' since Father Damien not only suffered from leprosy but made major contributions toward overcoming the very revulsion and misconceptions that are being decried. One could then further obfuscate society by speaking of the 'Two D's'. Unfortunately, society will want to know what 'Hansen's disease' is. Recognizing it as leprosy, society will then need the same rational explanation for its misconceptions that it should be challenged immediately with the same energetic efforts that are applied to promoting the attempted name change. 
Since the opprobrium attached to leprosy has been largely emotional in origin and expression, it would seem to be more effective to eschew the emotional and seck the rational in counterattack. Acceptance of the history of leprosy and society's reaction to it for the unpleasant fact that it is, paves the way for attempted understanding and refutation of the misconceptions. It is more important and effective to understand the misconceptions than to hide from them. Indeed, even in the West it is impossible to hide from them for literature is too replete with the disastrous and odious connotations.

I.cprosy is unique. It is unique in the peculiarly intense reaction it has called forth in diverse societies. It is also unique in the imuno-pathologic complex that gives it its identity. Perhaps one may find a relationship between these areas of uniqueness that will be explanatory.

THE REIATIONSHIP OF THE SOCIAL TO THE

MEDICAL PATHOLOGY OF LEPROSY

From a knowledge of general pathology and from an understanding of the social reaction to leprosy, one may postulate a disease characterization that would be most likely to breed such a reaction (skinsNes, I 9.58).

$\mathrm{I}$. The disease would be externally manifest. Many discases cause their greatest havoc internally without obvious external, specific manifestation, and since this deformation is not evident to the public eyc such diseases are unlikely to breed strong reaction especially in medically unversed socicty.

The discase, therefore, would have a predominant dermal component with swelling, ulceration, etc. Also, such a skin disease would be likely to ensure disfiguring changes over much of the body.

2. The disease would be progressively crippling and deforming. The rclentless progression of a deformity is likely to be more disconcerting, especially if also associated with progressive loss of function, than is a crippling effect that appears suddenly and then remains stationary. Further, progressive crippling, especially when prolonged, throws an ever increasing economic strain on society which is especially irritating when resources are limited and facilitics for care of the disabled are absent.

The most effective manner of achieving this irritant characteristic would be for the disease to cause progressive involvement of nerves of the extremitics and face. Such involvement would not be a ready hazard to life, would add to the visual horror created by the dermal manifestations, and would have the facility to progressively impair some of the senses by which man reacts to and preserves himself in nature and society. At the same time such a sufferer would remain aware of his plight since his central nervous system would not be impaired.

3. The disease would be non-fatal and chronic, with an unusually long course. Some diseases have marked external manifestations, but their course is short, resulting either in recovery or death in a relatively short period. 
Some of these, for example smallpox, may afflict a community, causing fear and horror, but the epidemic passes and community immunity builds up. Such epidemics are likely to affect whole communities. 'They have becn looked on as special visitations from the gods, directed at a whole community or society. 'The society may then fecl united in affliction, and perhaps in wrongdoing, rather than being revolted by certain 'punished' individuals.

The most effective manner of accomplishing this end might be for the disease to be non-fatal but debilitating so that the sufferer would in due course be susceptible to also other, secondary disease ravages.

4. The disease would have an insidious onset. 'This feature would make it liable also to whatever opprobrium related disease manifestations would have. Also, it would be a good way to bedevil and confuse the 'scholar'.

5. The disease would have fairly high endemicity but not be epidemic. A rare, or relatively rare illness, e.g. pemphigus, of frightening appearance might well be dismissed by society as an oddity, or perhaps a strange personal affliction, but a common disease would demand action and explanation.

6. The incidence and continuance of the disease would be associated with low community standards of living. A low standard of living with concomitant low standards of knowledge and education provides a favourable milieu for the development of superstitions and misconceptions. Or, as in GrecoRoman and ancient Chinese times, though the standard of cducation may have been good when available, the level of medical knowledge may be inadequate to the challenge.

One way to accomplish this association would be for the disease to be transmitted primarily by person to person contact and to have such a low degree of infectivity that prolonged contact under crowded and perhaps unhygienic conditions would be necessary for usual transmission. Or, the same effect could be accomplished by coupling low infectivity with high, but not complete, natural immunity on the part of the major portion of the community.

Another mechanism of achieving this effect would be for transmission to be accomplished by insect vectors. This would be less effective in achieving world-wide spread under otherwise favourable conditions since the distribution of most insects is affected by climatic factors.

7. The disease would appear to be incurable. This might be due to actual incurability by means available to society or apparent incurability because of residual deformity.

8. As a master-stroke, the disease would have a long incubation period. A long lapse of time between infection and manifestation of disease reduces significantly the likelihood of establishing the source of the infection, 
especially when the infecting agent is invisible to the unaided eyc. In a society where superstition and magical explanations of observed phenomena are in voguc, a long incubation period might well add the mysterious touch that would cause the disease to appear as if striking from the unknown, that is, as if it were a special punishment from heaven or 'the gods'.

A variety of mechanisms or combinations of mechanisms might be responsible for a long incubation period as, for example, a long generation time, ability to lic dormant for long periods, low tissue irritability and low immunogenicity on the part of the infecting agent.

Clearly, the discase complex postulated is that characteristic of and reflecting leprosy. The underlying reasons for this disease pattern are now beginning to be understood, and the characteristics of the inciting agent include such factors as long gencration time, low immunogenicity, apparent ability to resist digestion by host cells to a considerable degrec, as well as other incompletcly understood characteristics that play into the picture (sKINSNEs, in press, c).

Each of the characteristics of the postulated disease complex can be found in a variety of diseases and are not individually unique. The complex provided by the association of all these characteristics in one disease entity is, however, unique to leprosy. It appears that it is this complex and its uniqueness which is responsible for the unique social reaction to leprosy.

Informants have reported that in some societies, usually limited in area, where leprosy is endemic there is little social reaction to the disease. In some such instances the information may be faulty in that the folklore and customs of the people are not adequately explored or understood by the observer who often is of different racial and national origin than the people reported on. In other instances, however, it seems that there is no significant pattern of opprobrium related to the disease. It may be that in such areas religious and ethical patterns do not demand explanations of the type that are called for in the majority of societics. An alternate possibility is that the pattern of leprosy manifestation may be different, e.g. milder, less crippling, inconspicuous incidence, etc., and therefore not as provocative as elsewhere. Racial and geographical variations in the immuno-pathologic type of leprosy and associated degree of crippling are recognized. For the present insufficient information is at hand to enable an explanatory choice to be made between these and perhaps also other possibilities.

\section{CONCLUSIONS}

I. The pattern of social abhorrence and persistent reaction to leprosy is unique among diseases in its intensity, inventiveness and ubiquity.

2. The presence of this reaction and behaviour pattern is not an evidence of unique racial or national benightedness but is remarkably similar in major cultures of both the Orient and the Western world and reaches far back into antiquity. 
3. The social reaction to leprosy is not attributable to any specific writing (e.g. the Bible) or religious or $\epsilon$ thical formulation, though it is clear that the writings and records of any given society will perpetuate its concepts as well as reflect and record its reactions.

4. The social pathology respecting leprosy is related to, and called forth by the medical pathologic complex which is unique to leprosy and which gives the disease its entity.

5. An alternatively possible explanation, thus far unexplored, is that the ancient, persistent concepts and reactions to leprosy originated in one centre of ancient leprosy endemicity, e.g. possibly India, and then diffused Westward and Eastward, perhaps with the spread of the disease, to eventually become reflected in diverse folklores and writings. However, there is at the present no convincing evidence available regarding the origin and early spread of leprosy or of similar spread of reaction to the disease. In any case, granting such spread would not vitiate the relationship suggested between the social and medical pathology of leprosy.

6. Changing the name of the disease in an cffort to throw off or obscure the long-standing social reaction to it is a formidable task in view of the multiplicity of terms synonymous with leprosy in many languages, and in view of the weight of literature in which the term leprosy and its synonyms are irrevocably cmbedded.

7. It would seem that a more rational approach would be to acknowledge the weight of opprobrium while at the same time, through the light of understanding of its genesis, challenge society with rational understanding of its irrational fear.

8. Recent, real and continuing, advances in the treatment of leprosy are also the most potent therapy for its social pathology. They break the pattern of both the social pathology and medical pathology of the disease for they promise relief from the chronicity and deforming effects of the disease, and perhaps, in time, from the disease itself with consequent negation of the whole disease pattern which has so disturbed society. It makes possible the replacing of the picture of divine, irrevocable retribution with that of an understood disease subject to management and control. References

adams, F. (translator), The Extant Works of Aretaeus, the Cappadocian. (1856). London: The New Sydenham Society, pp. 368-372.

COCHrane, R. G., 'Biblical Leprosy - A Suggested Interpretation.' (1956). The Star, 15: 1-3 (reprinted article).

GRAMBERG, K. P. C. A., 'Leprosy and the Bible.' (1959), Trop. \& Geograph. Med., II : $127-139$. LENDrum, F. C., 'That Tragic Name of "Leprosy".' ( 1945), Modern Hospital, January.

skinsnes, O. K., Leprosy Rationale. (1 958), Hong Kong: Mission to Lepers, Hong Kong Auxiliary, (English and Chinese).

SkINSNEs, о. к., 'Leprosy in Society. I. "Leprosy has Appeared on the Face".' Lep. Review, 35: (1964), $21-35$.

SKINSNes, О. к., 'Leprosy in Society. II. 'The Pattern of Concept and Reaction to Leprosy in Oriental Antiquity.' Lep. Review, 35: (1964) 106-122.

skinsnes, о. к. 'The Immunologic Spectrum of Leprosy.' Leprosy in Theory and Practice, (1964), 156-182, ed. R. G. Cochrane and T. F. Davey. Bristol: John Wright \& Sons Ltd.

TAS, J., 'On the Leprosy of the Bible.' (1 953), Actes du 7e Congress Intern. d'Histoire des Sciences, a Jeruzalem, p: 583 ff. Reprinted in the Star, June 1955 . 